\title{
Isolation and HPLC quantitation of kaurane-type diterpenes and cinnamic acid derivatives of long-term stored leaves of Mikania laevigata and Mikania glomerata
}

\author{
SUZAN K.V. BERTOLUCCI ${ }^{1,2}$, ANA B.D. PEREIRA ${ }^{1}$, JOSÉ E.B.P. PINTO ${ }^{2}$, \\ ALAÍDE B. OLIVEIRA ${ }^{1}$ and FERNÃO C. BRAGA ${ }^{1}$ \\ ${ }^{1}$ Departamento de Produtos Farmacêuticos, Faculdade de Farmácia, Universidade Federal de Minas Gerais, \\ Av. Presidente Antônio Carlos, 6627, 31270-901 Belo Horizonte, MG, Brasil \\ ${ }^{2}$ Departamento de Agricultura, Universidade Federal de Lavras, Caixa Postal 3037, 37200-000 Lavras, MG, Brasil
}

Manuscript received on May 26, 2011; accepted for publication on May 8, 2012

\begin{abstract}
The leaves of Mikania laevigata and Mikania glomerata are used in Brazil to treat respiratory affections, being kaurane-type diterpenes and coumarin considered as the bioactive compounds. The present study reports an investigation on the HPLC-DAD profiles and contents of coumarin (1), trans-o-coumaric (2), kaurenoic (3), benzoylgrandifloric (4) and cinnamoylgrandifloric (5) acids in dried leaves of Mikania species stored in dark room under controlled conditions. Excepting 2, the constituents were isolated and purified to be employed as reference compounds. The samples were analyzed at three monthly intervals up to 18 months for M. laevigata and 12 months for M. glomerata. trans-o-Coumaric was not detected in both, whereas 1 occurred only in M. laevigata. The concentrations of the assayed constituents did not vary significantly within the evaluated period $(p<0.05)$, for both species. In contrast, changes in the chromatographic profiles and spectral purity of peaks from 3, $\mathbf{4}$ and $\mathbf{5}$ were detected in samples of both Mikania stored for three months, while the coumarin profile in M. laevigata modified after six months of storage. The evaluation of chromatographic profiles based on spectral purity analyses of selected peaks was shown to be a more robust tool to access chemical stability of Mikania samples than the quantitation of chemical markers' contents.
\end{abstract}

Key words: chemical markers changes, HPLC-DAD analysis, Mikania laevigata, Mikania glomerata, storage, post-harvest.

\section{INTRODUCTION}

The validation of medicinal plants has only gained attention of the Brazilian scientific community and government in the last decade (Bertolucci et al. 2009); for that reason, the quality control of herbal drugs in the country is limited by the reduced number of chemical markers

Correspondence to: Fernão Castro Braga

E-mail: fernao@netuno.lcc.ufmg.br defined for native species, along with the lack of commercial sources of reference compounds (Braga et al. 2003).

Different chromatographic techniques are employed for the quality control of vegetal drugs and herbal products including qualitative and quantitative methods based on TLC, HPLC and GC analyses (Liang et al. 2009, RazmovskiNaumovski et al. 2010). Chromatographic methods 
are extensively used for the quality control of plant raw materials due to their ability to detect variations in chemical composition originated from intraspecific differences, growing conditions, harvest time, processing methods and storage period (Liang et al. 2009). The development of HPLC methods for plant analysis is not straightforward and involves exhaustive optimization of operating conditions (e.g., mobile phase composition, $\mathrm{pH}$, column and temperature) in order to obtain desirable outcomes such as higher plate number, shorter analysis times, peak purity and improved peak resolution (Dharmadi and Gonzalez 2005) - this last in the case of simultaneous analysis of multiple compounds.

Mikania laevigata Schultz Bip. ex Baker and Mikania glomerata Sprengel (Asteraceae) are medicinal species popularly known as guaco, widely used in Brazil to treat respiratory affections (Napimoga and Yatsuda 2010). Kaurane-type diterpenes from the ent-series [kaurenoic (KA), benzoylgrandifloric (BA) and cinnamoylgrandifloric (CA) acids] and the derivatives of cinnamic acid, coumarin (CO) and trans-o-coumaric acid (OC) (Fig. 1) have been identified as constituents of the species (Veneziani and Oliveira 1999, Vilegas et al. 1997, Oliveira et al. 1984) and may account for their alleged biological properties (Ambrosio et al. 2006, Moura et al. 2002). Previous reports have suggested similar chemical composition for the leaves of both Mikania (Veneziani and Oliveira 1999, Vilegas et al. 1997, Oliveira et al. 1984). However, we reported a marked difference in the constitution of M. laevigata and M. glomerata leaves, with the presence of KA, $\mathrm{BA}$ and $\mathrm{CA}$ in both and the lack of $\mathrm{CO}$ and $\mathrm{OC}$ in the last one (Bertolucci et al. 2009). Besides, we found higher contents of BA and CA in M. laevigata, while KA was disclosed as the most abundant compound in M. glomerata (Bertolucci et al. 2009).

Safety and efficacy of phytopharmaceutical products are directly affected by the chemical reliability at all stages of the manufacturing processes, including stability and shelf-life of vegetal drugs (Sahoo et al. 2010). Nevertheless, there are only a few reports addressing post-harvest effects, storage and shelf-life of medicinal plants (Guimarães et al. 2011, Madan et al. 2008, Stafford et al. 2005, Fennell et al. 2004, Griggs et al. 2001). As far as we know, storage-related changes in the constituents of Mikania species have never been investigated. Taking into account that cinnamic acid derivatives and kaurane-type diterpenes are considered the bioactive compounds of guaco, the goal of the present study was to investigate the HPLC profiles and contents of $\mathrm{CO}, \mathrm{OC}, \mathrm{KA}, \mathrm{BA}$ and $\mathrm{CA}$ in stored leaves, thus requiring the isolation of some of them to be employed as reference compounds.

\section{MATERIALS AND METHODS}

\section{GENERAL EXPERIMENTAL PROCEDURES}

Fractionation of the extracts and purification of the isolated compounds were carried out by column chromatography on silica gel 60G (Merck 0.2-0.5 mm and Merck 0.063-0.200 mm) and by preparative TLC on self-coated plates with silica gel 60G (Merck, 70-230 $\mu \mathrm{m}$ ). LiebermannBurchard, $p$-anisaldehyde and NP/PEG solutions were employed as spray reagents for monitoring the fractionation, along with ammonium vapor exposure, the detection was carried out under UV light at 254 and $366 \mathrm{~nm}$ (Wagner et al. 1984).

A Shimadzu preparative HPLC system composed of LC-8A quaternary pump, SCL-8A controller, SPD-6AV UV-VIS detector and CR4A integrator was employed for the final purification of the compounds. Analyses were performed on Shimpack Prep Sil $(250 \times 10 \mathrm{~mm}$ d.i., Shimadzu $)$ and Shim-pack Prep-ODS $(250 \times 10 \mathrm{~mm}$ d.i. $)$ columns. Purity of the isolated compounds was checked by melting point data (without correction) determined on MQAPF-301 apparatus (Microquímica), HPLCDAD and NMR analysis, whereas their identification was accomplished by spectroscopic analysis (UV, 
IR, ${ }^{1} \mathrm{H}$ and ${ }^{13} \mathrm{C}$ NMR). IR spectra were recorded on a Perkin-Elmer FT-IR spectrophotometer in ATR mode with internal reference (range 4,000$\left.600 \mathrm{~cm}^{-1}\right) .{ }^{1} \mathrm{H}$ and ${ }^{13} \mathrm{C}$ NMR spectra were obtained on Bruker Avance DRX-200 and DRX-400 equipments (Departamento de Química, UFMG), operating respectively at 200 and $400 \mathrm{MHz}$ for ${ }^{1} \mathrm{H}$ and at 50 and $100 \mathrm{MHz}$ for ${ }^{13} \mathrm{C}$. TMS was employed as internal standard for both nuclei and $\mathrm{CDCl}_{3}$ solutions were used in the analyses. Optical rotations were determined using a Bellingham Stanley ADP220 automatic recording spectropolarimeter. The analyses of chemical markers were carried out on a Waters 2695 HPLC system composed of a quaternary pump model L-6200A, autosampler, in-line degasser AF (Waters) and photo-diode array detector (Waters 2996). Waters Empower software was employed for data processing. The analyses were performed on a LiChrospher 100 RP-18 column (125 × 4 mm i.d., $5 \mu \mathrm{m}$; Merck $)$, in combination with a LiChrospher 100 RP-18 guard column $(4 \times 4 \mathrm{~mm}$ i.d., $5 \mu \mathrm{m}$; Merck $)$.

\section{ISOLATION AND SPECTROSCOPIC CHARACTERIZATION OF}

CHEMICAL MARKERS

Mikania glomerata and Mikania laevigata leaves were collected from specimens cultivated at the Departamento de Agricultura, Universidade Federal de Lavras, Minas Gerais, Brazil. The leaves were collected in summer (January, 2004), from the apical, intermediate and basal regions of 16-month old plants, cultivated under solar radiation.

The species were identified by Dr. Mara Rejane Ritter from the Instituto de Biociências, Universidade Federal do Rio Grande do Sul, Porto Alegre, Brazil, where vouchers are deposited under the codes ICN 141992 and ICN 141990, respectively. The leaves were dried in a ventilated oven at $40^{\circ} \mathrm{C}$ for $72 \mathrm{~h}$. The dried materials $(2 \mathrm{~kg}$ of Mikania glomerata and $4 \mathrm{~kg}$ of Mikania laevigata) were ground in a knife mill, following exhaustive percolation with ethanol $96 \%$ at room temperature. Solvent was removed in a rotatory evaporator and the obtained extracts were kept in desiccators until the complete elimination of the residual solvent. The obtained crude extracts (331.6 g of M. glomerata and $564.9 \mathrm{~g}$ of M. laevigata) were employed for the isolation of chemical markers.

Mikania laevigata extract $\left(\begin{array}{ll}500 & \text { g}\end{array}\right)$ was fractionated by silica gel column chromatography affording the $n$-hexane $(6.76 \mathrm{~g}), \mathrm{CH}_{2} \mathrm{Cl}_{2}(139.54 \mathrm{~g})$, EtOAc (35.06 g) and $\mathrm{MeOH}(283.82 \mathrm{~g})$ fractions. The $n$-hexane fraction was mainly composed by impure CO. The EtOAc fraction (35.06 g) was refractionated over a silica gel column to yield $\mathrm{L}_{2}$ (20.82 g) eluted with $n$-hexane $/ \mathrm{CH}_{2} \mathrm{Cl}_{2}$ (7:3). In the sequence, $\mathrm{L}_{2}$ was submitted to silica gel column chromatography to give pure CO (191.1 mg; eluent: $n$-hexane $/ \mathrm{CH}_{2} \mathrm{Cl}_{2} 4: 6$ ), along with the sub-fractions $\mathrm{L}_{3} \mathrm{~K}$ (2.10 g; eluent: $\mathrm{CH}_{2} \mathrm{Cl}_{2} /$ EtOAc 9:1) and $\mathrm{L}_{3} \mathrm{~N}$ (268.9 mg; eluent: $\mathrm{CH}_{2} \mathrm{Cl}_{2} / \mathrm{EtOAc}$ 8:2). Further fractionation of $\mathrm{L}_{3} \mathrm{~K}$ over a silica gel column afforded $\mathrm{L}_{4} \mathrm{~F}$ (499.7 mg; eluent: $n$-hexane $/ \mathrm{CH}_{2} \mathrm{Cl}_{2}$ 4:6) and BA (404.7 mg; eluent: $n$-hexane $/ \mathrm{CH}_{2} \mathrm{Cl}_{2}$ 2:8). The final purification of $\mathrm{L}_{4} \mathrm{~F}$ by preparative HPLC employing isocratic elution with $n$-hexane/ $\mathrm{Et}_{2} \mathrm{O}(7: 3)$ on a silica gel column afforded KA (7.8 $\mathrm{mg}) . \mathrm{L}_{3} \mathrm{~N}$ was chromatographed over a silica gel column eluted with $n$-hexane/Et ${ }_{2} \mathrm{O}(9: 1)$ to give CA (96.6 mg). OC was purchased from Sigma-Aldrich.

Mikania glomerata extract $(5 \times 32 \mathrm{~g})$ was submitted to sonication with EtOAc $(5 \times 150 \mathrm{~mL})$ for $15 \mathrm{~min}$. After removing the residue by filtration, each EtOAc-soluble fraction was partitioned with saturated sodium bicarbonate solution $(3 \times$ $100 \mathrm{~mL}$ ). The EtOAc fractions were combined and solvent was removed under reduced pressure to give a greenish residue $(18.2 \mathrm{~g})$. It was then dissolved in ethanol and treated several times with active charcoal, affording a whitish solid (300 mg), which was subjected to preparative HPLC on a silica gel column eluted with $n$-hexane/ $\mathrm{Et}_{2} \mathrm{O}$ (7:3) to give KA (34.8 mg). 
Spectroscopic data obtained for the isolated compounds were compared with literature records (Batista et al. 2005, Kupriyanova 1997, Fabbri et al. 1997, Velandia et al. 1998, Oliveira et al. 1984, Vichnewski et al. 1977, Rowbotham and Schaefer 1972). Coumarin (CO, $191 \mathrm{mg})$ : white solid, M.p. 70-72 ${ }^{\circ}$ C. Benzoylgrandifloric acid (BA, $404.7 \mathrm{mg}$ ): white solid, M.p. $183-186^{\circ} \mathrm{C}$. $[\alpha]_{\mathrm{D}}^{24}=-40^{\circ}(\mathrm{MeOH}$, c $2.0 \mathrm{mg} / \mathrm{mL}$ ). Kaurenoic acid (KA, $7.8 \mathrm{mg}$ from M. laevigata and $34.8 \mathrm{mg}$ from M. glomerata): amorphous colorless solid. $[\alpha]_{\mathrm{D}}^{24}=-100^{\circ}(\mathrm{MeOH}$, c $2.0 \mathrm{mg} / \mathrm{mL}$ ). Cinnamoylgrandifloric acid (CA, $96.6 \mathrm{mg})$ : white solid, M.p. $191-195^{\circ} \mathrm{C} .[\alpha]_{\mathrm{D}}^{24}=$ $-40^{\circ}(\mathrm{MeOH}$, c $2.0 \mathrm{mg} / \mathrm{mL})$.

DEVELOPMENT AND OPTIMIZATION OF HPLC CONDITIONS

FOR THE ANALYSIS OF CHEMICAL MARKERS

For the analysis, $1 \mathrm{~g}$ of dried leaves was submitted to ultrasound-assisted extraction with ethanol $(2 \times 30$ $\mathrm{mL}$ ), at room temperature ( $20 \mathrm{~min}$ each cycle). The extract was filtered through filter paper to a $100 \mathrm{~mL}$ volumetric flask and filled up with ethanol. An aliquot $(10 \mathrm{~mL})$ was taken and the solvent removed in a rotatory evaporator at $50^{\circ} \mathrm{C}$ under reduced pressure. The obtained residue was dissolved in $\mathrm{MeOH}(1 \mathrm{~mL})$ and centrifuged at $8,400 \mathrm{~g}$ for $10 \mathrm{~min}$, being the supernatant employed for analysis. During method development, fortified extracts of Mikania laevigata were prepared by adding OC to final concentration of $0.1 \mathrm{mg} / \mathrm{mL}$, whereas Mikania glomerata extracts were spiked with $\mathrm{OC}$ and $\mathrm{CO}$ (final concentrations of $0.1 \mathrm{mg} / \mathrm{mL}$ each) before sonication.

Method development and optimization comprised the modification of parameters related to chromatographic resolution, including organic modifier, temperature, flow rate and slope of gradient elution. Phosphoric acid $0.1 \%$ was added to the eluents in all assayed conditions. Peak identification was based on UV data recorded on line by $\mathrm{DAD}$, as well as on the co-injection of reference compounds. Chromatographic selectivity was accessed by analyzing UV spectra recorded by DAD in the ascending, upper and descending regions of the peaks, being considered pure those peaks whose spectra matched exactly. The condition was considered selective when all five analyzed chemical markers showed adequate peak purity.

The efficiency of the established chromatographic condition was also assessed by determining system suitability parameters (resolution, retention factor, tailing and number of plates) of the chemical markers. The parameters were determined using Waters Empower software according to the equations recommended by the United States Pharmacopoeia (USP 2006) and the results were the mean value of 6 replicates. Determination of $t_{0}$ was accomplished by the injection of $10 \mu \mathrm{L}$ of sodium nitrate solution $0.01 \%(\mathrm{~m} / \mathrm{v})$ prepared in $\mathrm{MeOH}$.

\section{ANALYSES OF CHEMICAL MARKERS IN STORED LEAVES}

Leaves of Mikania laevigata and Mikania glomerata were collected in June 2007 from the apical, intermediate and basal regions of cultivated 45-month old plants ( $n=6$ plants for each species). The fresh leaves were conditioned in kraft paper bags and dried in a ventilated oven at $40^{\circ} \mathrm{C}$ until constant weight. The paper bags were transferred into polypropylene bags and stored in a dark room with controlled temperature $\left(25 \pm 5^{\circ} \mathrm{C}\right)$ and humidity (54 $\pm 20 \%)$. M. glomerata and M. laevigata samples were stored during 12 and 18 months, respectively.

Samples of the stored material were analyzed at three-month intervals. The leaves were ground in a knife mill, sieved in 0.85 $\mathrm{mm}$ tamis and freezer stored $\left(-20^{\circ} \mathrm{C}\right)$ in safelock polypropylene bags until analysis. The developed chromatographic method was applied to assess changes in the chemical markers during storage of the plant material. Analysis was based on peak purity disclosed by UV spectral curves recorded on line for $\mathrm{CO}, \mathrm{OC}, \mathrm{BA}, \mathrm{CA}$ 
and KA. The contents of these compounds were quantified using a method previously described by us (Bertolucci et al. 2009).

\section{STATISTICAL ANALYSIS}

Statistical design was entirely casualized delineation, with 7 treatments for Mikania laevigata $\left(\mathrm{T}_{0}, \mathrm{~T}_{3}, \mathrm{~T}_{6}, \mathrm{~T}_{9}, \mathrm{~T}_{12}, \mathrm{~T}_{15}\right.$ and $\mathrm{T}_{18}$, respectively to experiment start and 3-18 months of storage) and 5 treatments for Mikania glomerata $\left(\mathrm{T}_{0}, \mathrm{~T}_{3}, \mathrm{~T}_{6}, \mathrm{~T}_{9}\right.$ and $\mathrm{T}_{12}$ ) with 6 repetitions each. The contents of constituents were submitted to ANOVA, followed by the Scott-Knott test, employing Sisvar software, version 5.0 (Ferreira 2007). Data were considered significantly different when $p<0.05$.

\section{RESULTS AND DISCUSSION}

ISOLATION OF CHEMICAL MARKERS

The crude ethanolic extracts from the leaves of Mikania laevigata and Mikania glomerata were fractionated to isolate the major compounds in the species, to be employed as chemical markers. Fractionation of $M$. laevigata afforded coumarin (CO) and three ent-kaurane diterpenes, namely benzoylgrandifloric (BA), kaurenoic (KA) and cinnamoylgrandifloric (CA) acids. KA was also isolated from M. glomerata extract. Structure identification of the isolated compounds was achieved by usual spectroscopic analysis and comparison with previously reported data (Kupriyanova 1997, Oliveira et al. 1984, Rowbotham and Schaefer 1972, Batista et al. 2005, Velandia et al. 1998, Fabbri et al. 1997, Vichnewski et al. 1977), as well as by TLC and HPLC analysis employing authentic samples.

The occurrence of the isolated compounds in the leaves of Mikania laevigata and Mikania glomerata was investigated by HPLC analysis, along with trans-o-coumaric acid (OC), a biosynthetic precursor of coumarin. Identification of the peaks corresponding to the isolated compounds was achieved by comparison with retention time, UV spectra and co-injection of reference compounds. Altogether, these data allowed us to propose $\mathrm{OC}, \mathrm{CO}$, $\mathrm{KA}, \mathrm{BA}$ and CA as chemical markers for M. laevigata, whereas only kaurane-type diterpenes (KA, BA and CA) were found in M. glomerata leaves.

HPLC-DAD PROFILE OF MIKANIA LAEVIGATA ETHANOL EXTRACT

Development and optimization of the HPLC-DAD method comprised the evaluation of 14 different conditions. Mikania laevigata was selected for method development in view of its more complex profile than Mikania glomerata. A sample spiked with OC was employed for method development due to the low intensity of its peak found in the exploratory run. Acetonitrile and methanol were tested as organic modifiers; ACN exhibited better resolution for the kaurane diterpenes, whereas $\mathrm{MeOH}$ improved resolution for the cinnamic acid derivatives. Therefore, both solvents were employed for elution. The chromatographic conditions were defined after exhaustive adjustment in the elution strength, gradient slope, temperature and flow rate. Despite several attempts to improve resolution, elution of BA and CA was partially superimposed to other peaks (Fig 1a). Spectral data recorded by DAD for BA and CA indicated maximum wavelength absorptions at 230 and $270 \mathrm{~nm}$, respectively, while the partially coeluted compounds showed maximum absorption at $210 \mathrm{~nm}$. Given that all previous attempts to increase resolution for the kaurane derivatives had failed, we selected different wavelengths to register the chemical markers, respectively $210 \mathrm{~nm}$ for $\mathrm{OC}, \mathrm{CO}$ and KA, $230 \mathrm{~nm}$ for BA and $270 \mathrm{~nm}$ for $\mathrm{CA}$, thus resulting in spectral purity for each chemical marker peak. The established conditions allowed the unambiguous identification of the five constituents in the leaves of M. laevigata. Finally, we introduced a timed wavelength program for 
chemical markers detection, allowing registering them at the wavelength of maximum absorbance in one single chromatogram (Fig. 1b). The established chromatographic conditions are described in Table I.
The reliability of the established conditions was checked by system suitability tests, comprising evaluation of resolution(Rs), tailing factor(T), number of plates $(\mathrm{N})$, retention factor $(k)$ and repeatability
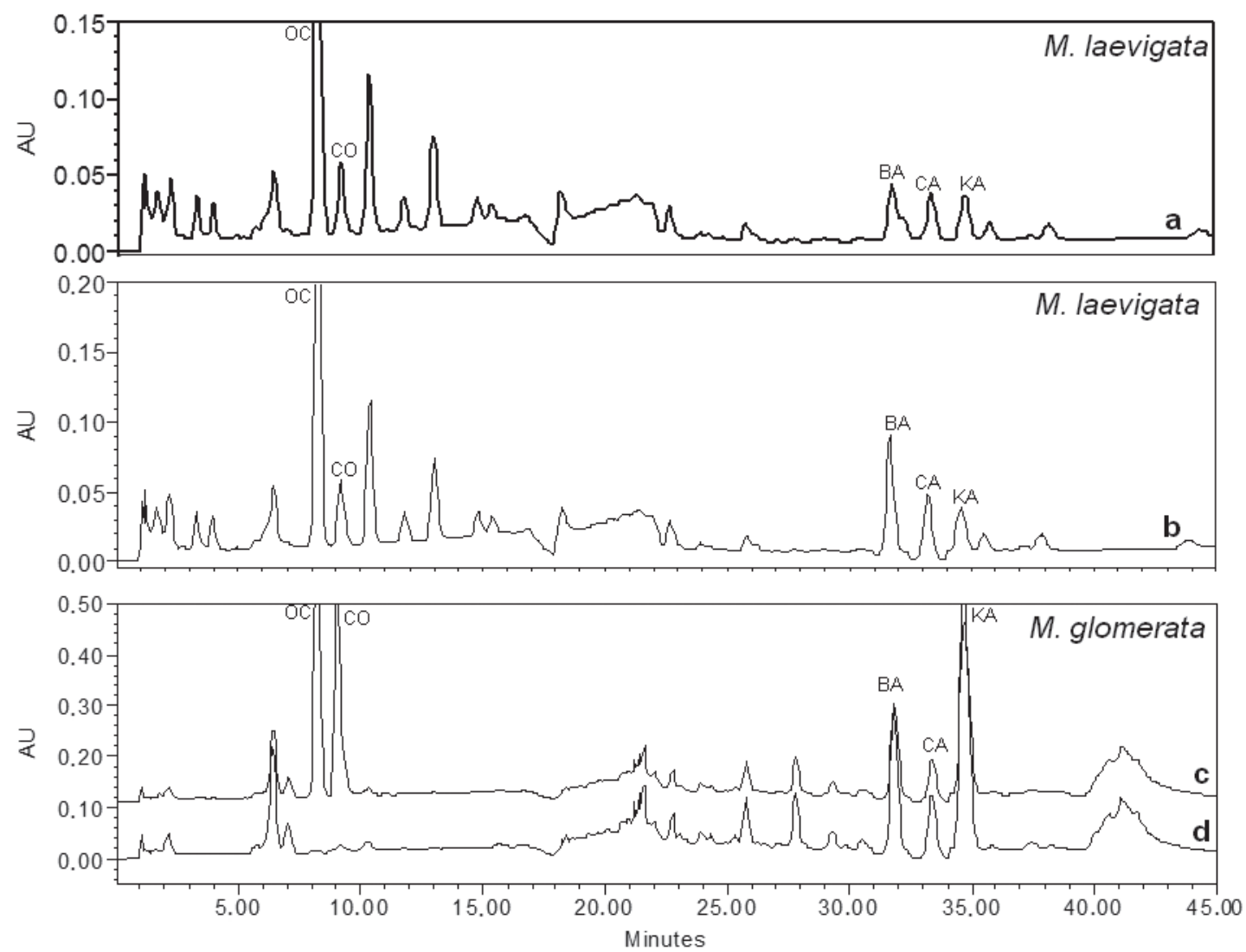

Figure 1 - HPLC profiles obtained for Mikania laevigata $(\mathrm{a}, \mathrm{b})$ and Mikania glomerata $(\mathrm{c}, \mathrm{d})$ employing the conditions described in Table I. The chromatograms were recorded using the timed wavelength program, except in "a", registered at $210 \mathrm{~nm}$. The sample in "a", "b" and "c" were spiked with $o$-coumaric acid, along with coumarin in "c". Peaks: OC, trans-o-coumaric acid; CO, coumarin; BA, ent-benzoylgrandifloric acid; CA, ent-cinnamoylgrandifloric acid; KA, ent-kaurenoic acid.

of peak response $[\mathrm{RSD}$ of retention time $(n=6)$ for chemical markers' peaks]. The results are presented in Table II, along with the limits recommended by the U.S. Food and Drug Administration (FDA 2000). All values are in accordance with FDA recommendations, excepting the resolution between $\mathrm{CO}$ and OC. Such finding may not constitute a problem, since it is accepted that system suitability tests might be less rigorous for biological matrices and traces analysis
(Dong et al. 2001). Moreover, some authors consider Rs $\sim 1.5$ adequate for quantitative analysis (Meyer 1996, Dong et al. 2001). Precision is critical for analytical routine methods; variation in retention time between runs indicates low precision. In the established method, a maximum RSD for retention time was observed for $\mathrm{CO}(0.40 \%)$, attesting the high reproducibility of the chromatographic conditions, including a sufficient re-equilibration interval. 
TABLE I

Chromatographic conditions established for the analysis of chemical markers in Mikania laevigata and Mikania glomerata leaves.

\begin{tabular}{cccc}
\hline $\begin{array}{c}\text { Time } \\
(\mathrm{min})\end{array}$ & $\begin{array}{c}\text { Water } \\
(\%)^{\mathrm{a}}\end{array}$ & $\begin{array}{c}\text { Methanol } \\
(\%)^{\mathrm{a}}\end{array}$ & $\begin{array}{c}\text { Acetonitrile } \\
(\%)^{\mathbf{a}}\end{array}$ \\
\hline 0 & 66 & 34 & 0 \\
15 & 50 & 50 & 0 \\
16 & 60 & 0 & 40 \\
20 & 35 & 0 & 65 \\
38 & 24 & 0 & 76 \\
38.1 & 5 & 0 & 95 \\
40 & 5 & 0 & 95 \\
45 & 66 & 34 & 0 \\
55 & 66 & 34 & 0 \\
\hline
\end{tabular}

${ }^{a}$ All eluents were acidified with $0.1 \%$ phosphoric acid. Analyses were carried out at $25^{\circ} \mathrm{C}$, at a flow rate of $1.0 \mathrm{~mL} /$ min, using a timed wavelength program $(0-30 \mathrm{~min}, 210 \mathrm{~nm}$; 31-32.4 min, $230 \mathrm{~nm}$; 32.5-34 min, $270 \mathrm{~nm}$ and 34.1-45.0 $\min , 210 \mathrm{~nm}$ ).
HPLC-DAD PROFILE OF MIKANIA GLOMERATA ETHANOL EXTRACT

The HPLC conditions employed to record Mikania laevigata profile were applied to Mikania glomerata samples, disclosing kaurane-type diterpenes as major constituents (Fig. 1d). However, the occurrence of $\mathrm{CO}$ in the species has been previously reported (Santos et al. 2006, Oliveira et al. 1984) and therefore the chromatographic conditions were not modified, since coumarin might be present in other samples of M. glomerata.

Similarly to Mikania laevigata, system suitability tests were carried out for Mikania glomerata (Table II). All analyzed parameters fell within the limits established by FDA (FDA 2000), excepting the resolution for KA. In spite of that, the obtained value $(\mathrm{Rs}=1.73)$ may be considered adequate for quantitative analysis (Dong et al.

TABLE II

System suitability parameters determined for the analysis of chemical markers in Mikania laevigata and Mikania glomerata leaves, employing the chromatographic conditions described in Table I.

\begin{tabular}{|c|c|c|c|c|c|c|}
\hline \multirow{2}{*}{ Chemical markers } & \multicolumn{6}{|c|}{ Parameters $^{\mathrm{a}}$} \\
\hline & $\mathbf{R}_{\mathrm{S}}$ & $\mathbf{T}$ & $\mathbf{N}$ & $k$ & $t_{\mathrm{R}}(\min )$ & $\mathbf{t}_{\mathrm{R}} \mathbf{R S D}$ \\
\hline \multicolumn{7}{|c|}{ Mikania laevigata } \\
\hline $\mathrm{OC}^{\mathrm{b}}$ & 1.88 & 1.05 & 5,125 & 6.69 & 8.24 & 0.32 \\
\hline $\mathrm{CO}$ & 1.88 & 1.19 & 5,085 & 7.57 & 9.18 & 0.40 \\
\hline BA & 2.62 & 1.10 & 43,398 & 28.58 & 31.78 & 0.09 \\
\hline $\mathrm{CA}$ & 2.62 & 1.09 & 43,175 & 30.06 & 33.27 & 0.03 \\
\hline KA & 2.03 & 1.08 & 42,024 & 31.42 & 34.76 & 0.08 \\
\hline \multicolumn{7}{|c|}{ Mikania glomerata } \\
\hline $\mathrm{OC}^{\mathrm{b}}$ & 1.70 & 1.08 & 5,614 & 6.66 & 8.22 & 0.24 \\
\hline $\mathrm{CO}^{a}$ & 1.70 & 1.39 & 5,055 & 7.43 & 9.05 & 0.31 \\
\hline BA & 2.51 & 1.12 & 44,944 & 28.68 & 31.82 & 0.05 \\
\hline $\mathrm{CA}$ & 2.51 & 1.09 & 43,920 & 30.06 & 33.27 & 0.03 \\
\hline KA & 1.73 & 1.19 & 40,122 & 31.36 & 34.69 & 0.05 \\
\hline $\begin{array}{l}\text { FDA }(2000) \\
\text { recommended values }\end{array}$ & $>2$ & $\leq 2$ & $>2,000$ & $>2.0$ & - & $\leq 1 \%, n \geq 5$ \\
\hline
\end{tabular}

${ }^{\text {a }}$ The parameters were determined in the wavelength established for each chemical marker, according to the program describe in Table I. Rs: resolution; T: tailing factor; $\mathrm{N}$ : plate number; $k$ : retention factor; $\mathrm{t}_{\mathrm{R}}$ : retention time; RSD: relative standard deviation. ${ }^{\mathrm{b}}$ Samples of Mikania laevigata and Mikania glomerata spiked with $0.1 \mathrm{mg} / \mathrm{mL}$ o-coumaric acid were employed in the experiments. See text for details. CO, coumarin; OC, trans-o-coumaric acid; BA, ent-benzoylgrandifloric acid; CA, ent-cinnamoylgrandifloric acid; KA, ent-kaurenoic acid. 
2001), as previously discussed for M. laevigata. Besides, spectral homogeneity attested peak purity for the three kaurane diterpenes, indicating method selectivity for $M$. glomerata.

Considering that the analyzed Mikania species present different matrices and that $\mathrm{CO}$ and $\mathrm{OC}$ may occur in other samples of Mikania glomerata, evaluation of method selectivity was also mandatory for this species. A sample of M. glomerata was spiked with $\mathrm{OC}$ and $\mathrm{CO}$ and the resulting chromatogram exhibited peak purity for both compounds (Fig. 1c). System suitability tests carried out for these chemical markers in the fortified sample of M. glomerata were also in accordance with FDA recommendations (FDA 2000), apart from the resolution of OC and CO, attesting method selectivity and precision (Table II).

The results obtained so far indicate a marked difference in the analyzed samples of Mikania laevigata and Mikania glomerata, with the presence of the kaurane-type derivatives (KA, BA and $\mathrm{CA}$ ) in both and the lack of the cinnamic acid derivatives (CO and $\mathrm{OC}$ ) in the second species. This finding corroborates the absence of coumarin previously reported for specimens of $M$. glometara collected in distinct locations of São Paulo state, Brazil (V.L.G. Rehder et al., unpublished data).

However, we cannot assure that cinnamic acid derivatives are not produced by Mikania glomerata, since both $\mathrm{CO}$ and $\mathrm{OC}$ have been already reported for the species (Santos et al. 2006, F. Bras. IV 2005, Veneziani and Oliveira 1999, Oliveira et al. 1984). The conflicting data may arise from misidentification of Mikania species based exclusively on foliar morphology, as described for the medicinal species Maytenus ilicifolia Mart. ex Reiss. and Maytenus aquifolium Mart. (Duarte and Debur 2005, Tiberti et al. 2007). The HPLC-DAD profiles here reported may contribute to overcome this problem and together with DNA fingerprints they will represent useful tools for the identification of Mikania laevigata and M. glomerata, allowing their unambiguous use for production of phytopharmaceuticals.
CHEMICAL MARKERS ANALYSIS DURING STORAGE

The HPLC profiles and quantitative composition of samples from Mikania leavigata and Mikania glomerata leaves, stored under controlled conditions, were analyzed three-monthly. $\mathrm{CO}$ and $\mathrm{OC}$ were not detected in M. glomerata within the evaluated period (Fig. 2, Table III), whereas CO was present in $M$. laevigata (Fig. 3, Table III). After six months of storage, peak purity analysis of $\mathrm{CO}$ revealed a coeluted compound, clearly detected in 12-month and 18-month stored plants (Fig. 4, CO), whose spectral data is compatible with a cinnamic acid derivative.

The CO content of 18-month stored plants $(0.124 \pm 0.026 \%)$ was statistically similar to time zero samples $(0.113 \pm 0.033 \%)(p<0.05$; Table III). Likewise, the concentration of the kaurane diterpenes did not vary significantly within the evaluated storage period $(p<0.05)$, for both species (Table III). However, spectral analysis of the peaks pointed out co-eluting compounds in samples of Mikania laevigata and Mikania glomerata stored for 6 and 3 months, respectively (data not shown). A marked decrease in resolution between CA and KA peaks $\left(\mathrm{R}_{\mathrm{S}}=0.93\right)$ was detected in M. laevigata after 9 months of storage in comparison to the experiment start $\left(R_{S}=2.62\right)$. This finding cannot be related to the loss of column efficiency, since the chromatograms obtained for non-stored plants showed similar resolution to $\mathrm{T}_{0}$ samples (data not shown).

UV data recorded on line for BA peak showed co-eluting compounds in samples of Mikania glomerata stored for 3 months (Fig. 4, BA), similarly to the peak of KA in the same species (data not shown). Besides, a marked decrease in resolution was observed for both compounds. Altogether the results suggest the occurrence of chemical transformations in these derivatives. Considering that changes in the peaks of kaurane diterpenes were observed after 3 months of $M$. glomerata storage, the stability study of this species was discontinued after 12 months. 


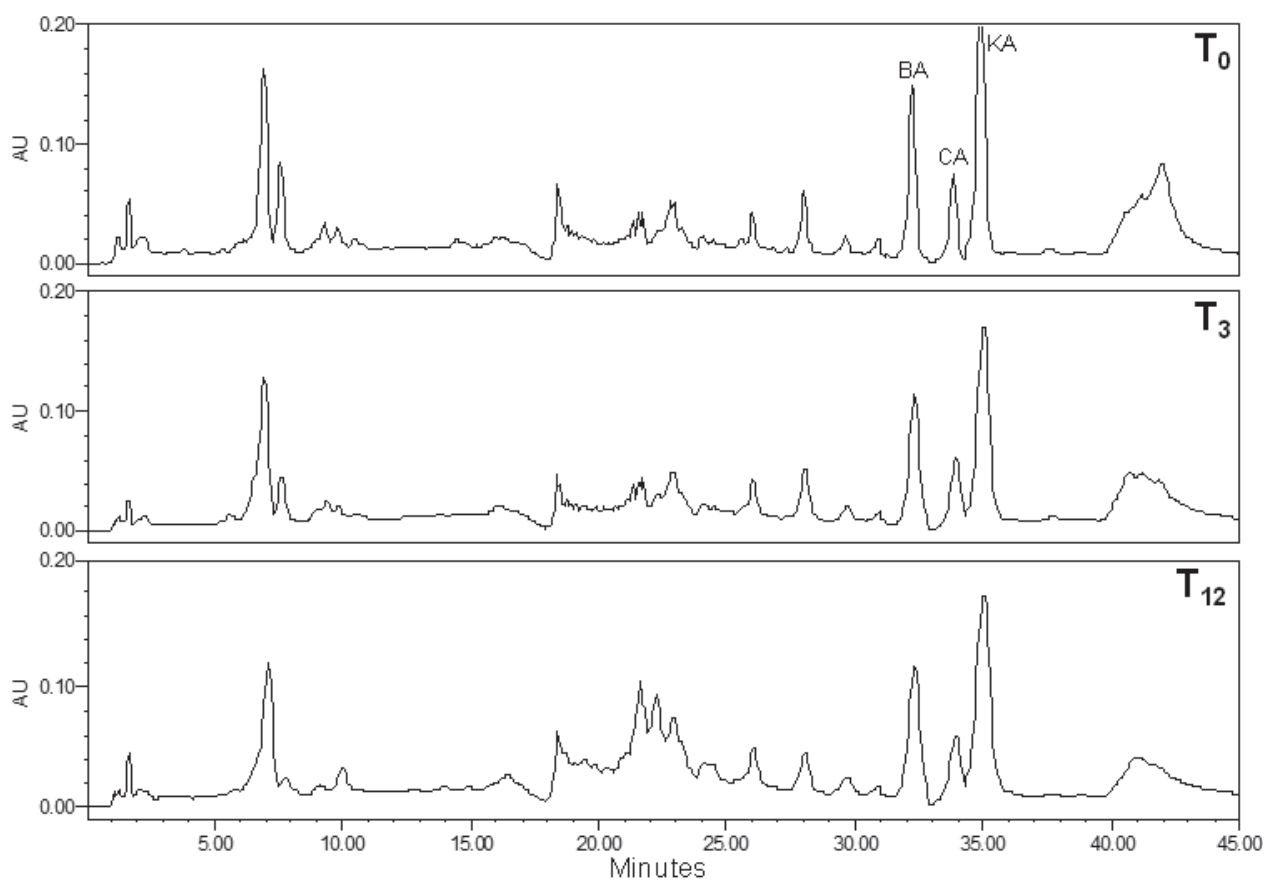

Figure 2 - HPLC profiles recorded for stored samples from Mikania glomerata leaves. Chromatographic condition: see Table I. Peaks: BA, ent-benzoylgrandifloric acid; CA, ent-cinnamoylgrandifloric acid; $\mathrm{KA}$, ent-kaurenoic acid. Storage periods: $\mathrm{T}_{0}$, study start; $\mathrm{T}_{3}, 3$ months; $\mathrm{T}_{12}, 12$ months.
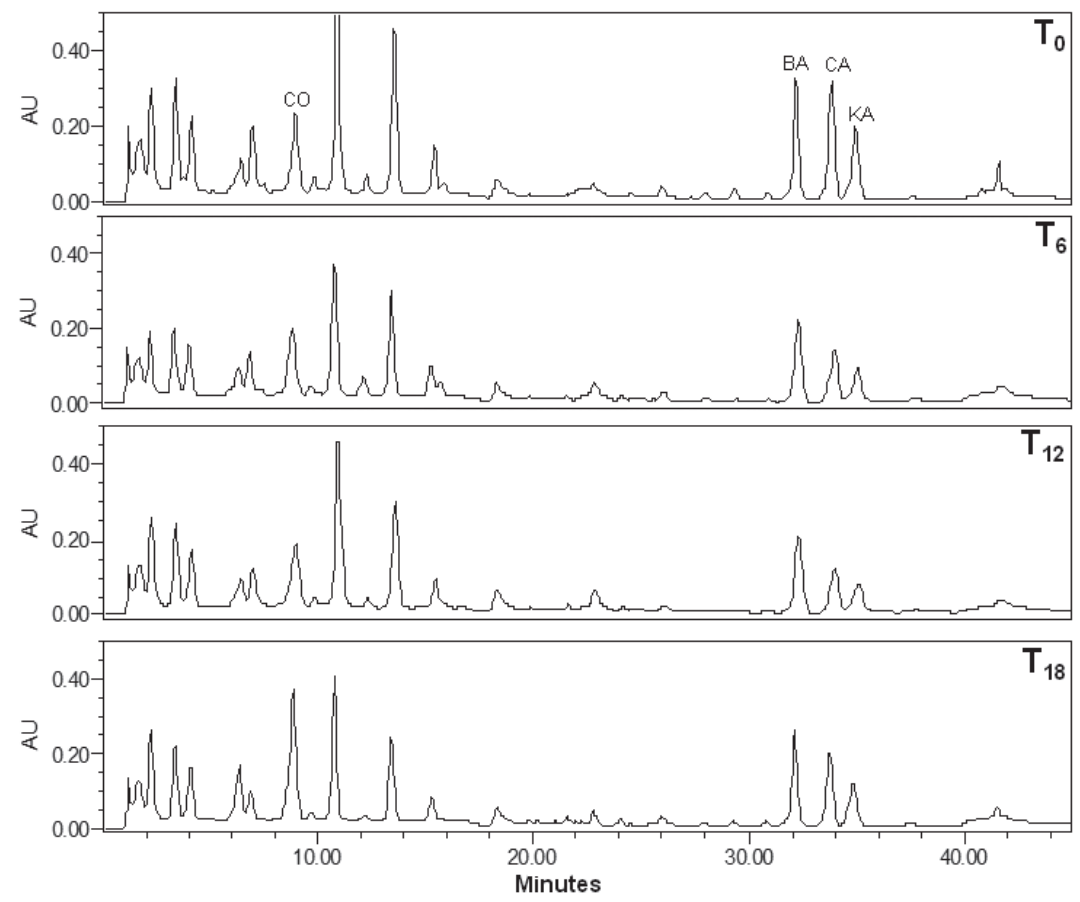

Figure 3 - HPLC profiles recorded for stored samples from Mikania laevigata leaves. Chromatographic condition: see Table I. Peaks: CO, coumarin; BA, ent-benzoylgrandifloric acid; CA, ent-cinnamoylgrandifloric acid; KA, ent-kaurenoic acid. Storage periods: $\mathrm{T}_{0}$, study start; $\mathrm{T}_{6}, 6$ months; $\mathrm{T}_{12}, 12$ months; $\mathrm{T}_{18}, 18$ months. 
TABLE III

Contents of chemical markers in stored samples from Mikania laevigata and Mikania glomerata leaves.

\begin{tabular}{|c|c|c|c|c|c|}
\hline \multirow{2}{*}{ Storage period $^{b}$} & \multicolumn{5}{|c|}{ Content of chemical markers $\left(\%\right.$ in dried leaves) ${ }^{a}$} \\
\hline & CO & OC & BA & $\mathbf{C A}$ & KA \\
\hline \multicolumn{6}{|c|}{ Mikania laevigata } \\
\hline $\mathrm{T}_{0}$ & $0.113 \pm 0.033$ & nd & $0.276 \pm 0.051$ & $0.208 \pm 0.060$ & $0.377 \pm 0.102$ \\
\hline $\mathrm{T}_{3}$ & $0.104 \pm 0.025$ & nd & $0.288 \pm 0.080$ & $0.201 \pm 0.064$ & $0.273 \pm 0.072$ \\
\hline $\mathrm{T}_{6}$ & $0.105 \pm 0.022$ & nd & $0.311 \pm 0.084$ & $0.219 \pm 0.080$ & $0.404 \pm 0.148$ \\
\hline $\mathrm{T}_{9}$ & $0.102 \pm 0.031$ & nd & $0.292 \pm 0.036$ & $0.179 \pm 0.047$ & $0.346 \pm 0.106$ \\
\hline $\mathrm{T}_{12}$ & $0.090 \pm 0.031$ & nd & $0.334 \pm 0.025$ & $0.144 \pm 0.029$ & $0.302 \pm 0.054$ \\
\hline $\mathrm{T}_{15}$ & $0.108 \pm 0.036$ & nd & $0.297 \pm 0.029$ & $0.176 \pm 0.044$ & $0.322 \pm 0.078$ \\
\hline $\mathrm{T}_{18}$ & $0.124 \pm 0.026$ & nd & $0.313 \pm 0.025$ & $0.142 \pm 0.025$ & $0.279 \pm 0.053$ \\
\hline \multicolumn{6}{|c|}{ Mikania glomerata } \\
\hline $\mathrm{T}_{0}$ & nd & nd & $0.198 \pm 0.027$ & $0.079 \pm 0.018$ & $0.964 \pm 0.160$ \\
\hline $\mathrm{T}_{3}$ & nd & nd & $0.189 \pm 0.012$ & $0.087 \pm 0.019$ & $0.879 \pm 0.140$ \\
\hline $\mathrm{T}_{6}$ & nd & nd & $0.176 \pm 0.017$ & $0.073 \pm 0.009$ & $0.779 \pm 0.109$ \\
\hline $\mathrm{T}_{9}$ & nd & nd & $0.174 \pm 0.014$ & $0.072 \pm 0.006$ & $0.847 \pm 0.120$ \\
\hline $\mathrm{T}_{12}$ & nd & nd & $0.180 \pm 0.009$ & $0.066 \pm 0.004$ & $0.759 \pm 0.060$ \\
\hline
\end{tabular}

\footnotetext{
${ }^{\mathrm{a}}$ Values are mean \pm standard error obtained by triplicate analyses; nd = not detected. The mean values within each column do not differ significantly by the Scott-Knott test $(p<0.05)$. ${ }^{\mathrm{b}}$ Storage periods evaluated: $\mathrm{T}_{0}$, study start; $\mathrm{T}_{3}, 3$ months; $\mathrm{T}_{6}, 6$ months; $\mathrm{T}_{9}, 9$ months; $\mathrm{T}_{12}, 12$ months; $\mathrm{T}_{15}, 15$ months; $\mathrm{T}_{18}, 18$ months. CO, coumarin; OC, trans-o-coumaric acid; BA, ent-benzoylgrandifloric acid; CA, ent-cinnamoylgrandifloric acid; KA, ent-kaurenoic acid.
}

Spectral purity evaluation of selected peaks was shown to be a robust tool to access chemical stability of both guaco species, complementary to quantitative analysis. Excepting CA and KA peaks, whose chromatograms clearly indicated loss of resolution during the storage periods (Fig. 2 and 3 ), chemical changes in the other compounds were only detected by peak purity analysis, since the contents of the constituents showed no significant variation for both species $(p<0.05)$.

In summary, our results demonstrate that the chemical integrity of the kaurane diterpenes (BA, CA and KA), constituents of Mikania glomerata and Mikania laevigata, is affected after three months of storage, whereas modifications in the coumarin peak, found only in M. laevigata, are detected after six months of storage. The Brazilian
Pharmacopoeia establishes a minimum content of $0.1 \%$ CO for M. laevigata (F. Bras. IV 2005), while the concentrations of kaurane diterpenes in Mikania species are not regulated by any official guide. The CO contents determined for stored samples of $M$. laevigata ranged from $0.10 \%$ to $0.12 \%$ and therefore fulfill the pharmacopoeical requirement, except for the 12-month sample (Table II). Hence, based strictly on the official guidelines, the analyzed samples would be considered adequate for human consumption. However, peak purity analyses of the constituents in stored samples indicate chemical changes, that may affect the biological effects of the vegetal drugs. Therefore, pharmacological analyses are required to investigate if the observed changes in chemical markers will affect the biological efficacy and safety of guaco. 

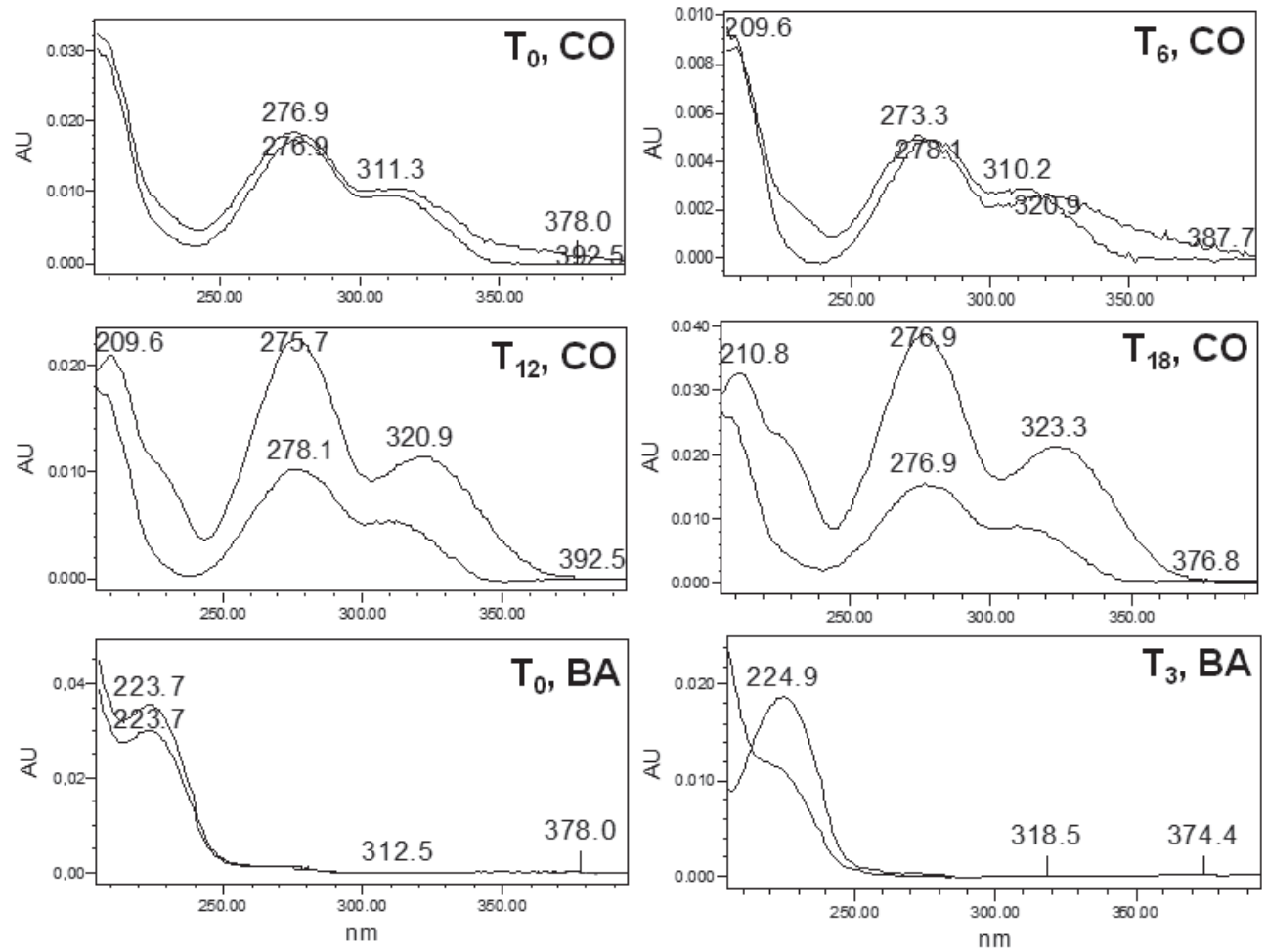

Figure 4 - UV spectra recorded on line by DAD in the ascending and descending regions of the peaks from coumarin (CO) and benzoylgrandifloric acid (BA) found in the chromatographic profiles of Figures 3 and 2, respectively. Storage periods: $\mathrm{T}_{0}$, study start; $\mathrm{T}_{3}, 3$ months; $\mathrm{T}_{6}, 6$ months; $\mathrm{T}_{12}, 12$ months; $\mathrm{T}_{18}, 18$ months.

\section{ACKNOWLEDGMENTS}

The authors are thankful to Conselho Nacional de Desenvolvimento Científico e Tecnológico (CNPq/ Brazil) for financial support and for research fellowships (ABO, FCB and JEBPP). Coordenação de Aperfeiçoamento de Pessoal de Nível Superior (CAPES/Brazil) is acknowledged for a $\mathrm{PhD}$ fellowship (SKVB) and Fundação de Amparo à Pesquisa do Estado de Minas Gerais (FAPEMIG/ Brazil) for an undergraduate (ABDP) fellowship. The authors are also grateful to Dr. Mara Rejane Ritter, Instituto de Biociências, UFRGS, Porto Alegre, Brazil, for identifying the plant species and to Dr. José Dias de Souza Filho, Departamento de Química, ICEX, UFMG, Belo Horizonte, Brazil, for the NMR analyses.

\section{RESUMO}

As folhas de Mikania laevigata e Mikania glomerata são usadas no Brasil para tratar afecções respiratórias, sendo diterpernos caurânicos e cumarina considerados os constituintes bioativos. O presente estudo relata a investigação dos perfis por CLAE-DAD e os teores de cumarina (1), ácidos trans-o-coumárico (2), caurenóico (3), benzoilgrandiflórico (4) e cinamoilgrandiflórico (5) em folhas secas de espécies de Mikania armazenadas em sala escura, sob condições controladas. Com exceção de $\mathbf{2}$, os constituintes foram isolados e purificados para serem empregados como substâncias de referência. As amostras foram analisadas trimestralmente, até um período de 18 meses para M. laevigata e 12 meses para M. glomerata. Ácido trans-o-coumárico não foi detectado em ambas as espécies, enquanto 1 foi encontrado somente em M. laevigata. As concentrações dos constituintes 
quantificados não variaram significativamente no período avaliado $(p<0,05)$, para duas espécies. Por outro lado, alterações nos perfis cromatográficos e na pureza espectral dos picos relativos a 3, 4 e 5 foram detectadas em amostras de ambas as espécies de Mikania armazenadas por três meses, enquanto o perfil do pico correspondente a cumarina mostrou-se alterado em $M$. laevigata a partir do sexto mês de armazenamento. A análise dos perfis cromatográficos baseada na avaliação da pureza espectral dos picos selecionados mostrou-se uma ferramenta mais robusta para acessar a estabilidade química de amostras de Mikania submetidas a armazenamento do que a quantificação do teor dos marcadores químicos.

Palavras-chave: marcadores químicos, análises por CLAE-DAD, Mikania laevigata; Mikania glomerata, estocagem, pós-colheita.

\section{REFERENCES}

Ambrosio SR, TIRAPElli CR, COSTA FB AND OliVEIRA AM. 2006. Kaurane and pimarane-type diterpenes from Viguiera species inhibit vascular smooth muscle contractility. Life Sci 79: 925-933.

Batista R, BRAga FC AND OliveIRA AB. 2005. Quantitative determination by HPLC of ent-kaurenoic and grandiflorenic acids in aerial parts of Wedelia paludosa D.C. Rev Bras Farmacogn 15: 119-125.

Bertolucci SKV, Pereira ABD, Pinto JEBP, Ribeiro JAA, OliveIRA AB AND BRAGA FC. 2009. Development and validation of a RP-HPLC method for quantification of cinnamic acid derivatives and kaurane-type diterpenes in Mikania laevigata and Mikania glomerata. Planta Med 75: 280-285.

Braga FC, VAladares YM, COSTA MA, LOMBARdi JA AND OLIVEIRA AB. 2003. Estudo fitoquímico de Erythraea centaurium, Jacaranda caroba, Remijia ferruginea e Solanum paniculatum visando identificar marcadores químicos para o fitoterápico Ierobina $^{\circledR}$. Rev Bras Farmacogn 13: 28-31.

DhARMADI Y AND GonZALEZ R. 2005. A better global resolution function and a novel iterative stochastic search method for optimization of high-performance liquid chromatographic separation. J Chromatogr A 1070: 89-101.

Dong M, PAul R AND Gershanov L. 2001. Getting the peaks perfect: system suitability for HPLC. Today's chemist at work 10: $38-40$

DUARTE MR AND Debur MC. 2005. Stem and leaf morphoanatomy of Maytenus ilicifolia. Fitoterapia 76: 41-49.

F. BRAS. IV. 2005. Farmacopéia Brasileira, $4^{\text {a }}$ ed., São Paulo: Atheneu, $292 \mathrm{p}$.
FABBRI H, OLIVEIRA DCR, VICHNEWSKI W AND HERZ W. 1997. Diterpenes of Mikania lindbergii Baker. Biochem Syst Ecol 25: 563-564.

FDA. 2000. Guidance for Industry, Analytical Procedures and Methods Validation. U.S. Food and Drug Administration: Rockville. URL [http://www.fda.gov/ cder/guidance/4252fnl.pdf]; accessed Nov 2008.

FenNELl CW, Light ME, Sparg SG, StafFord GI AND STADEN JV. 2004. Assessing African medicinal plants for efficacy and safety: agricultural and storage practices. J Ethnopharmacol 95: 113-121.

FERREIRADF. 2007. SISVAR 5.0: sistema de análise estatística. Lavras: UFLA/DEX. Software.

GRIGGS JK, MANANDHAR NP, TOWERS GHN AND TAYLOR RSL. 2001. The effects of storage on the biological activity of medicinal plants from Nepal. J Ethnopharmacol 77: 247-252.

Guimarães R, Barreira JCM, Barros L, CARVAlho AM AND FERREIRA ICFR. 2011. Effects of oral dosage form and storage period on the antioxidant properties of four species used in traditional herbal medicine. Phytother Res 25: 484-492.

KUPRIYANOVA GS. 1997. NMR studies of the electronic structure of coumarins. J Struct Chem 38: 408-414.

Liang X, JinA Y, WANGA Y, Jin G, FUA Q AND XiaO Y. 2009. Qualitative and quantitative analysis in quality control of traditional Chinese medicines. J Chromatogr A 1216: 2033-2044.

MADAN VK, YADAV OP AND TYAGI CS. 2008. Post harvest degradation of saponin content in powder of Asparagus racemosus tubers with different drying and storage methods. Acta Horticult 776: 261-265.

MEYER VR. 1996. Practical high-performance liquid chromatography, $2^{\text {nd }}$ ed., New York: J Wiley \& Sons, 376 p.

MourA RS ET AL. 2002. Bronchodilator activity of Mikania glomerata Sprengel on human bronchi and guinea-pig trachea. J Pharm Pharmacol 54: 249-256.

NAPIMOGA MH AND YATSUDA R. 2010. Scientific evidence for Mikania laevigata and Mikania glomerata as a pharmacological tool. J Pharm Pharmacol 62: 809-820.

Oliveira F, Alvarenga MA, Akisue G and Akisue MK. 1984. Isolamento e identificação de componentes químicos de Mikania glomerata Sprengel e de Mikania laevigata Schultz Bip. ex Baker. Rev Farm Bioquím Univ S Paulo 20: 169-183.

Razmovski-NAUMOVSKI V, TONGKAO-ON W, Kimble B, QiaO VL, Beilun L, Li KM, Roufogalis B, Depo Y, MEICUN Y AND LI GQ. 2010. Multiple chromatographic and chemometric methods for quality standardisation of Chinese herbal medicines. Mode Tradit Chin Med Mater Med 12: 99-106.

RowBotham JB AND SCHAEFER T. 1972. Experimental and theoretical estimates of sigma and pi electron contributions to long-range spin-spin coupling constants in coumarin and its methyl derivatives. Can J Chem 51: 953-960.

SAHOO N, MANCHIKANTI P AND DEY S. 2010. Herbal drugs: standards and regulation. Fitoterapia 81: 462-471. 
Santos SC, Krueger CL, Steil AA, Kreuger Mr, BIAVATTI MW AND WISNIEWSKI JÚNIOR A. 2006. LC characterisation of guaco medicinal extracts, Mikania laevigata and $M$. glomerata, and their effects on allergic pneumonitis. Planta Med 72: 679-684.

StAFFORD GI, JÄGER AK AND VAN STADEN J. 2005. Effect of storage on the chemical composition and biological activity of several popular South African medicinal plants. J Ethnopharmacol 97: 107-115.

Tiberti LA, Yariwake JH, NDJOKo K AND HostetTManN K. 2007. Identification of flavonols in leaves of Maytenus ilicifolia and M. aquifolium (Celastraceae) by LC/UV/MS analysis. J Chromatogr B 846: 378-384.

USP. 2006. The United States Pharmacopeia: USP29-NF24. Rockville: The United States Pharmacopeial Convention, p. 2644-2649.

VELANDIA JR, CARVALHO MG AND BRAZ-FILHO R. 1998. Ácido ent-16 $\alpha, 17$-diidroxicauran-19-óico isolado de Ouratea semiserrata e os desafios estereoquímicos dos carbonos quirais C-4 e C-16. Química Nova 21: 397-404.
VENEZIANI RCS AND OLIVEIRA DCR. 1999. Constituents of Mikania glomerata Sprengel. Biochem Syst Ecol 27: 99-102.

VICHNEWSKI W, LEITÃo FILHO HF, MURARI R AND HERZ W. 1977. Cinnamoylgrandifloric acid from Mikania oblongifolia. Phytochemistry 16: 2028-2029.

VILEGAS JHY, MARCHI E AND LANÇAS FM. 1997. Determination of coumarin and kaurenoic acid in Mikania glomerata (guaco) leaves by capillary gas chromatography. Phytochem Anal 8: 74-77.

Wagner H, Bladt S And Zgainsky EM. 1984. Plant drug analysis: a thin layer chromatography atlas. Berlin: Springer Verlag, $320 \mathrm{p}$. 